\title{
Effects of eradication of Helicobacter pylori on oral malodor and the oral environment: a single-center observational study
}

\author{
Nao Suzuki 1,2* ${ }^{*}$, Richiko Beppu 3,7, Masahiro Yoneda4, Toru Takeshita5,6, Mikari Asakawa ${ }^{5}$, Yoshihisa Yamashita ${ }^{5}$,
} Takashi Hanioka' ${ }^{1}$ Takao Hirofuji ${ }^{4}$ and Tetsuo Shinohara ${ }^{3,8}$

\begin{abstract}
Objective: Although a relationship between Helicobacter pylori and oral malodor has been suggested, it remains to be confirmed. One reason for this is that many studies assess oral malodor subjectively. Another reason for the uncertainty is that the reduction in oral malodor may be due to the effect of antibiotics on the oral microbiota. In this study, changes in oral malodor along with the eradication treatment of $H$. pylori were investigated by organoleptic test and gas chromatography. In addition, the salivary bacterial composition and clinical parameters were analyzed.

Results: The organoleptic test score, hydrogen sulfide and dimethyl sulfide concentrations, and all clinical parameters except for tongue-coating score were significantly decreased at 1 week compared with baseline. Although antibiotic treatment also altered the overall composition of the salivary bacterial population, it had recovered at 7 weeks. On the date that H. pylori was determined to have been eradicated from all of the subjects ( 7 weeks after treatment), only the organoleptic test score was significantly lower compared with baseline. The hydrogen sulfide and dimethyl sulfide concentrations were non-significantly lower than those at baseline.
\end{abstract}

Keywords: Antimicrobial therapy, Helicobacter pylori, Oral bacteria, Oral malodor, Organoleptic test, Volatile sulfur compound

\section{Introduction}

A relationship between Helicobacter pylori and oral malodor has been known since the identification of $H$. pylori [1]. Upper gastrointestinal disorders can cause oral malodor, but oral malodor is linked to the oral cavity in $90 \%$ of cases [2]. Several cross-sectional studies have reported that $H$. pylori-infected individuals had oral malodor [3-5], but no difference in exhaled breath or stomach air [5] compared to uninfected individuals. Therefore, it has often been hypothesized that gastric or oral H. pylori

\footnotetext{
*Correspondence: naojsz@college.fdcnet.ac.jp

${ }^{1}$ Department of Preventive and Public Health Science, Fukuoka Dental College, Fukuoka, Japan

Full list of author information is available at the end of the article
}

infection alters oral conditions, possibly leading to oral malodor [6-8].

Observational studies of the effect of $H$. pylori eradication on oral malodor would help better to clarify the relationship between oral malodor and $H$. pylori infection [9-12]. Such studies should consider two points. First, it is necessary to evaluate oral malodor objectively. Prior studies assessed subjective symptoms of oral malodor using questionnaires and interviews; however, it is difficult for an individual to evaluate their own oral malodor accurately $[13,14]$. Second, it is necessary to clarify the effects of the antibiotics used for $H$. pylori eradication on the oral microbiota, since those antibiotics are reportedly effective against periodontal disease $[15,16]$.

In this study, we objectively evaluated oral malodor changes along with the eradication treatment of $H$. 
pylori by measuring the concentrations of volatile sulfur compounds (VSCs) by gas chromatography (GC) and organoleptic test (OLT) as the primary outcome. The secondary outcomes included oral symptoms and bacterial parameters. In addition, $16 \mathrm{~S}$ rRNA gene sequencing was performed to evaluate the direct effect of the antibiotics used to eradicate $H$. pylori on the oral microbiota.

\section{Main text}

\section{Materials and methods}

\section{Study design}

An observational study was conducted between September 2014 and May 2016. The study population comprised patients who presented with gastric symptoms and were diagnosed with $H$. pylori infection based on positive rapid urease tests conducted on gastric biopsy specimens. The inclusion criteria were as follows: 20 years or older, having own teeth, and no oral symptoms that require immediate treatment. Those with drug allergies and pregnant women were excluded. Twelve patients were analyzed (Additional file 1; Table S1). They were prescribed a 1-week course of a triple-drug regimen $(30 \mathrm{mg}$ lansoprazole, $750 \mathrm{mg}$ amoxicillin, and $200 \mathrm{mg}$ clarithromycin, twice daily) as the primary eradication regimen. In cases in which the primary treatment failed, $250 \mathrm{mg}$ metronidazole was used instead of clarithromycin as the secondary regimen.

\section{Clinical examinations}

Oral malodor and oral clinical symptoms were evaluated on the date of initiation of $H$. pylori eradication treatment and 1 and 7 weeks thereafter. The severity of oral malodor was determined by OLT [13] and GC. A gas chromatograph (GC2014; Shimadzu, Kyoto, Japan) was used to assay the concentrations of $\mathrm{H}_{2} \mathrm{~S}, \mathrm{CH}_{3} \mathrm{SH}$, and $\mathrm{CH}_{3} \mathrm{SCH}_{3}$ in mouth air. The average probing pocket depth (PPD), the percentage of bleeding on probing (BOP) values, the plaque index (PII) [17], and the tongue coating score (TCS) [14] were evaluated. The ammonia concentration was measured using a portable ammoniamonitoring device (ATTAIN; Taiyo, Osaka, Japan). Saliva samples were obtained by stimulation using chewing gum (CheckBuf; Morita, Osaka, Japan) and subjected to sequencing of the 16S rRNA gene amplicons and quantitative analysis of bacterial species. These examinations were conducted at $9 \mathrm{am}$; the subjects were prohibited from eating, drinking, chewing, smoking, brushing teeth, or rinsing their mouth after waking up.

\section{Quantitative analysis of bacterial species in saliva}

Quantitative analysis of 12 bacterial species and all bacteria in saliva was performed using the fibrous DNA chip Genopal $^{\circledR}$ (Mitsubishi Chemical, Tokyo, Japan). The bacterial species were classified into the red (Porphyromonas gingivalis, Tannerella forsythia, and Treponema denticola), orange (Campylobacter rectus, Fusobacterium nucleatum, Prevotella intermedia, and Prevotella nigrescens), green (Aggregatibacter actinomycetemcomitans and Capnocytophaga gingivalis), and yellow (Streptococcus gordonii, Streptococcus intermedius, and Streptococcus mutans) groups [18], and the proportions of these groups among the total oral bacteria were evaluated.

\section{Sequencing of 16S rRNA gene amplicons}

DNA was extracted from each saliva sample [19] and the V1-V2 regions of the 16S rRNA gene were amplified by PCR using the universal bacterial primers $8 \mathrm{~F}$ and $338 \mathrm{R}$ with adaptor and sample-specific 8-base tag sequences [20]. Following emulsion PCR, sequencing was performed on the Ion PGM using an Ion PGM Hi-Q View sequencing kit (Thermo Fisher Scientific, Waltham, MA). The raw sequencing reads were quality-filtered [21]. The quality-checked reads were assigned to the appropriate sample by examining the tag sequence. Similar sequences were assigned to operational taxonomic units (OTUs) using UPARSE [22], with a minimum pairwise identity of $97 \%$. The taxonomy of each representative sequence was determined using blast against oral bacterial 16S rRNA gene sequences in the Human Oral Microbiome Database [23]. Nearest-neighbor species with $\geq 98.5 \%$ identity were selected as candidates for each OTU. The taxonomy of an OTU without any hits was determined to the genus level using the Ribosomal Database Project classifier with a minimum support threshold of $80 \%$. The alpha diversity index and UniFrac distances [24] were calculated following rarefaction to 5000 reads per sample.

\section{Statistical analysis}

The Wilcoxon signed-rank test was used to compare malodor, clinical, and bacterial parameters among baseline, 1 week, and 7 weeks. The relative abundance of bacterial genera after 1 and 7 weeks were compared with those at baseline using Dunnett's test. Statistical analyses were conducted using R software, version 3.6.1 [25].

\section{Results}

\section{Oral malodor and clinical parameters}

Table 1 shows the changes of the oral malodor and clinical parameters. The values of all parameters decreased at 1 week compared with baseline, and the decreases in the OLT score, $\mathrm{H}_{2} \mathrm{~S}$ and $\mathrm{CH}_{3} \mathrm{SCH}_{3}$ concentrations, $\mathrm{PPD}, \mathrm{BOP}$, PII, and ammonia concentration were significant. On the date when $H$. pylori had been eradicated from all subjects, the values of all parameters other than the $\mathrm{CH}_{3} \mathrm{SH}$ concentration were lower than those at baseline but tended to be higher than those at 1 week. Only the OLT score 
Table 1 Clinical parameters at baseline, the date of treatment completion, and the date of eradication of $\boldsymbol{H}$. pylori

\begin{tabular}{llll}
\hline Parameter & Baseline & Date of treatment completion & $\begin{array}{l}\text { Determination } \\
\text { of date of successful } \\
\text { eradication }\end{array}$ \\
\hline OLT score & & & $1.75[1.19,2.00]^{*}$ \\
VSCs $(\mathrm{ng} / 10 \mathrm{~mL})$ & $2.25[1.50,3.00]$ & $1.50[0.89,1.56]^{*}$ & $1.57[0.78,5.23]$ \\
$\mathrm{H}_{2} \mathrm{~S}(\mathrm{ng} / 10 \mathrm{~mL})$ & $2.29[1.26,6.72]$ & $1.69[0.25,2.68]$ & $0.56[0.35,3.14]$ \\
$\mathrm{CH}_{3} \mathrm{SH}(\mathrm{ng} / 10 \mathrm{~mL})$ & $1.19[0.50,4.88]$ & $0.51[0.13,1.75]^{*}$ & $0.58[0.21,1.35]$ \\
$\mathrm{CH}_{3} \mathrm{SCH}(\mathrm{ng} / 10 \mathrm{~mL})$ & $0.55[0.36,1.24]$ & $0.29[0.09,0.95]$ & $0.32[0.24,0.55]$ \\
$\mathrm{PPD}(\mathrm{mm})$ & $0.60[0.38,0.70]$ & $0[0.00,0.43]^{*}$ & $3.0[2.93,3.02]$ \\
$\mathrm{BOP}(\%)$ & $3.02[2.98,3.24]$ & $3.0[2.92,3.02]^{*}$ & $4.74[2.22,14.0]$ \\
$\mathrm{Pll}$ & $7.64[2.98,21.0]$ & $4.27[1.74,6.33]^{*}$ & $0.65[0.35,0.84]$ \\
$\mathrm{TCS}$ & $0.67[0.21 .0 .83]$ & $0.29[0.21,0.39]^{*}$ & $1.50[1.00,2.00]$ \\
Ammonia $(\mathrm{ppm})$ & $2.00[1.75,2.00]$ & $1.00[1.00,2.00]$ & $30.0[20.0,50.0]$ \\
\hline
\end{tabular}

Median [IQR]

PII, plaque index; TCS, tongue-coating score; ${ }^{*} P<0.05$ vs. baseline by Wilcoxon signed-rank test

was significantly lower than that at baseline $(P=0.037)$. The comparisons between the success and failure groups after primary eradication treatment showed that the OLT score, total VSC concentration, BOP, and PPD in the failure group were increased slightly at 7 weeks, as compared with 1 week, but were unchanged in the success group (Additional file 2: Figure S1).

\section{Quantitative analysis of bacterial species in saliva}

The total bacterial amounts (median [IQR], log copies/ $\mathrm{mL}$ ) in saliva at baseline, 1 week, and 7 weeks with the primary eradication regimen were 7.7 [7.4-8.0], 7.4 [7.28.0], and 7.9 [7.5-8.1], respectively. The proportions of bacterial groups were compared in the success and failure groups with the primary eradication regimen (Table 2). The proportion of the red group was lower at 7 weeks than at baseline in both groups, although the difference was significant only in the success group $(P=0.039)$. In addition, the proportions of T. forsythia $(P=0.098)$ and
T. denticola $(P=0.098)$ were decreased at 7 weeks compared with baseline and at 1 week, respectively, albeit not significantly so (Additional file 3: Table S2). The proportions of $C$. rectus, $F$. nucleatum and $P$. nigrescens at baseline were non-significantly higher in the failure group than in the success group.

\section{Bacterial diversity and composition in saliva}

The alpha diversity index was decreased at 1 week compared with baseline in every individual and increased to the baseline level again on the determination of the date of $H$. pylori eradication by the primary regimen (Additional file 4: Figure S2). A UniFrac analysis demonstrated that antibiotic treatment for $H$. pylori infection altered the overall composition of the salivary bacterial populations, although they had recovered on the determination day of eradication (Fig. 1). The relative abundance of Rothia was significantly lower in the saliva at 1 week compared with baseline $(P=0.005)$, whereas no significant

Table 2 Bacterial groups in saliva by the primary eradication regimen outcome

\begin{tabular}{lllll}
\hline Bacterial group & Eradication & Baseline & 1 week & $\mathbf{7}$ weeks \\
\hline Red group & Success & $0.04[0.03,0.07]$ & $0.02[0.01,0.04]$ & $0.03[0.020 .03]^{*}$ \\
Orange group & Failure & $0.05[0.04,0.05]$ & $0.03[0.02,0.06]$ & $0.02[0.02,0.02]$ \\
& Success & $2.14[1.40,5.56]$ & $1.01[0.12,4.38]$ & $3.29[2.62,7.17]$ \\
Green group & Failure & $2.63[2.11,4.47]$ & $0.78[0.43,3.87]$ & $6.17[5.0,6.65]$ \\
& Success & $0.05[0.01,0.28]$ & $0.22[0.01,0.77]$ & $0.03[0.0,0.09]$ \\
Yellow group & Failure & $0.05[0.04,0.17]$ & $0.35[0.18,0.45]$ & $0.02[0.01,0.32]$ \\
& Success & $0.55[0.42,1.17]$ & $0.28[0.15,0.61]$ & $0.75[0.38,0.89]$ \\
\hline
\end{tabular}

Median [IQR]

${ }^{*} P<0.05$ vs. baseline by Wilcoxon signed-rank test

1 week, date of treatment completion. 7 weeks, determination of date of eradication 

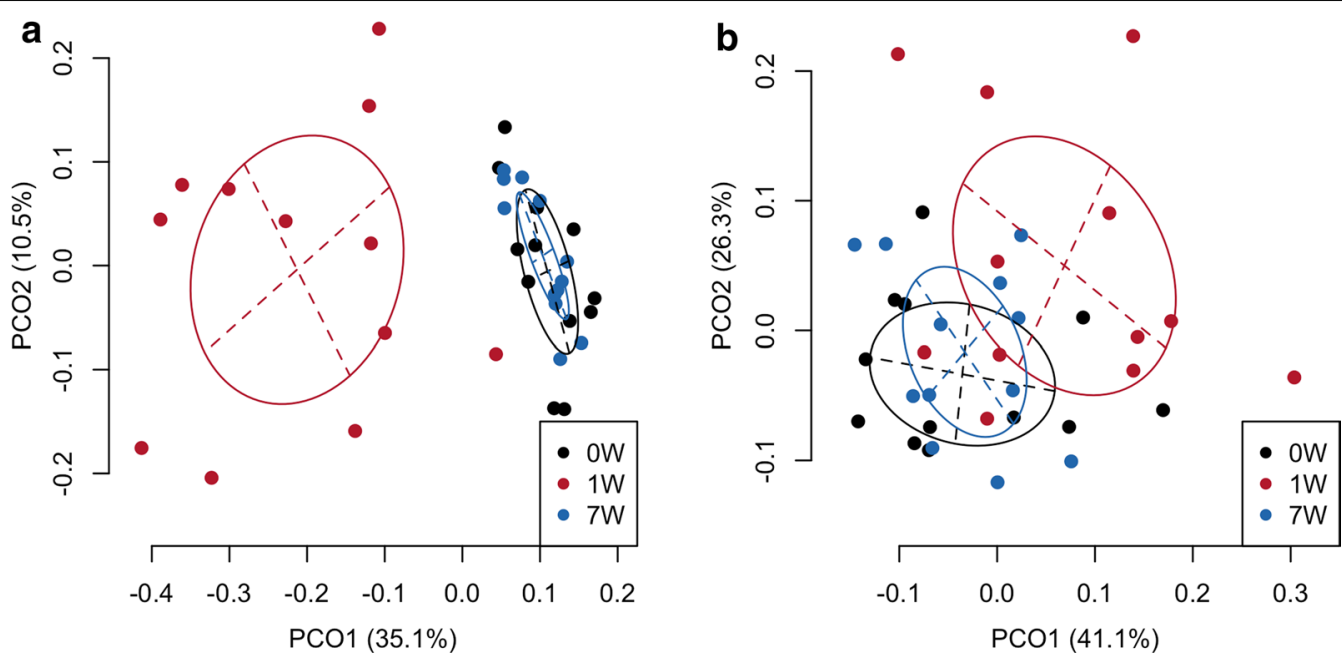

Fig. 1 A principal coordinate analysis ( $\mathrm{PCOA}$ ) plot showing the similarity relationship between saliva samples from 12 patients at three phases of treatment using unweighted (a) and weighted (b) UniFrac distance matrices with the primary eradication regimen. $0 \mathrm{~W}$, baseline; $1 \mathrm{~W}$, date of treatment completion (1 week); $7 \mathrm{~W}$, determination of date of $\mathrm{H}$. pylori eradication (7 weeks). The ellipse covers $67 \%$ of the samples belonging to each phase group

difference in the relative abundance of the genus was observed between baseline and the date of determining H. pylori eradication by the primary regimen (Additional file 5: Figure S3).

\section{Discussion}

A recent systematic review concluded that oral malodor is reduced by eradication of $H$. pylori [26]. However, most of the studies included in that review assessed subjective symptoms of oral malodor using a questionnaire $[11,12$, $27,28]$. Few studies have assessed oral malodor using a portable sulfide monitor or OLT [10, 29]. Oral malodor is influenced by psychological factors, and it is difficult for individuals to evaluate their own oral malodor accurately $[13,14]$. To elucidate the relationship between oral malodor and $H$. pylori infection, objective evaluations of oral malodor are needed, such as measuring odor components and OLT performed by experts. This is the first study to measure VSC concentrations by GC and to perform the OLT to evaluate the effect of $H$. pylori eradication on oral malodor objectively. As a result, the OLT score was significantly decreased after $H$. pylori eradication compared with baseline. In contrast, the concentrations of $\mathrm{H}_{2} \mathrm{~S}$ and $\mathrm{CH}_{3} \mathrm{SCH}_{3}$ were decreased on the date of eradication compared with baseline, albeit not significantly so. The amelioration of oral malodor was not due to a direct effect of antibiotics on oral bacteria, because the bacterial composition was not different from that before eradication and the total oral bacterial count was not significantly different between after $H$. pylori eradication and baseline. Use of antibiotics in combination with mechanical therapy for periodontal disease resulted in significant differences in the richness and dissimilarity of the oral microbiota after 2 months, whereas the evenness and diversity were not affected [30]. It is possible that the effect on the oral microbiota differs between antibiotics alone and antibiotics plus mechanical therapy. Concerning the significant reduction of the OLT score, ammonia, methylamine, dimethylamine, propionic acid, butyric acid, indole, skatole, and cadaverine may cause oral malodor in addition to VSCs [31]. More studies on the involvement of substances other than VSCs in oral malodor associated with $H$. pylori are needed.

After initiating the primary eradication regimen, there were differences in the clinical findings and the proportions of some bacterial species between the success and failure groups. We postulate that these differences are key to successful eradication. With the primary eradiation regimen, the OLT score, total VSC concentration, BOP, and PPD tended to increase slightly, after decreasing at 1 week, in the failure group, but these parameters remained low in the success group. The success group showed a significant decrease in the proportion of red complex species $(P=0.039)$. At 1 week, the proportions of S. gordonii and C. gingivalis were increased and decreased in the failure and success groups, respectively. The proportions of $C$. rectus, $F$. nucleatum, and $P$. nigrescens at baseline were higher in the failure group than in the success group. Periodontopathic bacteria such as $F$. nucleatum and $P$. nigrescens produce indole, skatole, and acetic, propionic, and butyric acids [32, 33]. Compared with the success group, the higher proportions of these 
bacteria in the failure group may be related to the higher OLT score at baseline, despite the lower VSC and PPD levels. C. rectus and $H$. pylori share several antigens that may play a role in the initiation and progression of periodontal disease [34, 35]. A high proportion of C. rectus may indicate active periodontal or gastric infection.

The ability of $\mathrm{H}$. pylori to produce $\mathrm{H}_{2} \mathrm{~S}$ and $\mathrm{CH}_{3} \mathrm{SH}$ is strain-specific [36]. H. pylori has been detected in oral specimens $[6,7,37]$, and its prevalence was associated with the progression of periodontitis. There is disagreement as to whether $H$. pylori is present in the oral cavity. The bacterial communities in the oral cavity are very complex, with over 500 species, and include many VSCproducing bacteria [2]. The oral malodor associated with H. pylori is unlikely to be caused by its production of VSCs, but rather by altering the oral environment and the populations of some oral bacteria. Chronic systemic inflammation and periodontitis interact via the systemic inflammatory response [38]. Thus, irrespective of the presence or absence of $H$. pylori infection in the oral cavity, gastric inflammation by $H$. pylori may exacerbate oral malodor via its effect on the oral environment.

\section{Limitations}

The current study included a small number of subjects.

\section{Supplementary information}

Supplementary information accompanies this paper at https://doi. org/10.1186/s13104-020-05253-5.

\section{Additional file 1: Table S1. Profile of the study population.}

Additional file 2: Figure S1. Oral malodor and clinical parameters in the H. pylori eradication success and failure groups after the primary eradication regimen.

Additional file 3: Table S2. Proportions of bacterial species in saliva by the primary eradication regimen outcome. Median [IQR].

Additional file 4: Figure S2. Changes in two alpha diversity indices, the number of OTUs (A) and the Shannon diversity index (B), in saliva after the primary eradication regimen. $0 \mathrm{~W}$, baseline; $1 \mathrm{~W}$, date of treatment completion (1 week); $7 \mathrm{~W}$, determination of the date of H. pylori eradication (7 weeks)

Additional file 5: Figure S3. Relative abundance of the predominant bacterial genera in saliva after the primary eradication regimen. Only genera with a mean relative abundance of $\geq 1 \%$ are shown. $0 \mathrm{~W}$, baseline: $1 \mathrm{~W}$, date of treatment completion (1 week); $7 \mathrm{~W}$, determination of the date of H. pylori eradication (7 weeks). ${ }^{*} P<0.01$, Dunnett's test (vs. baseline).

\section{Abbreviations}

BOP: Breeding on probing; GC: Gas chromatography; IQR: Interquartile range; Pll: Plaque index; OLT: Organoleptic test; OTU: Operational taxonomic unit; PPD: Probing pocket depth; TCS: Tongue coating score; VSC: Volatile sulfur compound.

\section{Acknowledgements}

We would like to thank Textcheck (www.textcheck.com) for English-language editing.

\section{Authors' contributions}

NS, TH, and TS designed the study, analyzed the data, and wrote the manuscript. NS and MY measured oral malodor and carried out the clinical assessments of the oral cavity. TH prepared the manuscript, specifically the visualization/data presentation. RB and TS invited patients to participate in the study and performed the medical assessments. TT, MA and YY analyzed the microbiota by $16 \mathrm{~S}$ rRNA sequencing. All authors read and approved the final manuscript.

\section{Funding}

This study was supported in part by a Grant-in-Aid for Scientific Research (C) (No. 26463175) from the Ministry of Education, Culture, Sports, Science and Technology (MEXT), Japan, and the Oral Medicine Research Center. Neither funding body had role in design of the study and collection, analysis, and interpretation of data and in writing the manuscript.

\section{Availability of data and materials}

The datasets used and analyzed during the current study are available from the corresponding author on reasonable request.

\section{Ethics approval and consent to participate}

All participants understood the nature of the research project and provided written informed consent to participate in this study. Permission for this study was obtained from the Ethics Review Committee for Clinical Research of Fukuoka Gakuen (No. 308)

\section{Consent for publication}

Not applicable.

\section{Competing interests}

The authors declare that they have no competing interests.

\section{Author details \\ ${ }^{1}$ Department of Preventive and Public Health Science, Fukuoka Denta College, Fukuoka, Japan. ${ }^{2}$ Oral Medicine Research Center, Fukuoka Dental College, Fukuoka, Japan. ${ }^{3}$ Department of General Medicine, Fukuoka Dental College, Fukuoka, Japan. ${ }^{4}$ Department of General Dentistry, Fukuoka Dental College, Fukuoka, Japan. ${ }^{5}$ Section of Preventive and Public Health Dentistry, Faculty of Dental Science, Kyushu University, Fukuoka, Japan. ${ }^{6}$ OBT Research Center, Faculty of Dental Science, Kyushu University, Fukuoka, Japan. ${ }^{7}$ Present Address: Department of Proctology, Fukuseikai Hospital, Fukuoka, Japan. ${ }^{8}$ Pre- sent Address: Department of Surgery, Fukuseikai Hospital, Fukuoka, Japan.}

Received: 29 March 2020 Accepted: 24 August 2020

Published online: 28 August 2020

References

1. Marshall BJ, Armstrong JA, McGechie DB, Glancy RJ. Attempt to fulfil Koch's postulates for pyloric campylobacter. Med J Aust. 1985;142:436-9.

2. Suzuki N, Yoneda M, Takeshita T, Hirofuji T, Hanioka T. Induction and inhibition of oral malodor. Mol Oral Microbiol. 2019:34:85-96.

3. Hajifattahi F, Hesari M, Zojaji H, Sarlati F. Relationship of halitosis with gastric Halicobacter pylori infection. J Dent (Tehran). 2015;12:200-5.

4. Hoshi K, Yamano Y, Mitsunaga A, Shimizu S, Kagawa J, Ogiuchi H. Gastrointestinal diseases and halitosis: association of gastric Helicobacter pylori infection. Int Dent J. 2002;52:207-11.

5. Tangerman A, Winkel EG, de Laat L, van Oijen AH, de Boer WA. Halitosis and Helicobacter pylori infection. J Breath Res. 2012;6:017102.

6. Aksit Bicak D, Akyuz S, Kiratli B, Usta M, Urganci N, Alev B, Yarat A, Sahin F. The investigation of Helicobacter pylori in the dental biofilm and saliva samples of children with dyspeptic complaints. BMC Oral Health. 2017;17:67.

7. Suzuki N, Yoneda M, Naito T, Iwamoto T, Masuo Y, Yamada K, Hisama K, Okada I, Hirofuji T. Detection of Helicobacter pylori DNA in the saliva of patients complaining of halitosis. J Med Microbiol. 2008;57:1553-9.

8. Adachi K, Notsu T, Mishiro T, Hiroo Y, Kinoshita Y. Influence of Helicobacter pylori infection on periodontitis. J Gastroenterol Hepatol. 2019;34:120-3.

9. Tiommy E, Arber N, Moshkiwitz M, Peled Y, Gilat T. Halitosis and Helicobacter pylori: a possible link? J Clin Gastroenterol. 1992;15:236-7. 
10. lerardi E, Amoruso A, La Notte T, Francavilla R, Castellaneta S, Marrazza E, Monno RA, Francavilla A. Halitosis and Helicobacter pylori: a possible relationship. Dig Dis Sci. 1998;43:2733-7.

11. Shashidhar H, Peters J, Lin CH, Rabah R, Thomas R, Tolia V. A prospective trial of lansoprazole triple therapy for pediatric Helicobacter pylori infection. J Pediatr Gastroenterol Nutr. 2000;30:276-82.

12. Katsinelos P, Tziomalos $K$, Chatzimavroudis $G$, Vasiliadis $T$, Katsinelos $T$, Pilpilidis I, Triantafillidis I, Paroutoglou G, Papaziogas B. Eradication therapy in Helicobacter pylori-positive patients with halitosis: long-term outcome. Med Princ Pract. 2007;16:119-23.

13. Yaegaki K, Coil JM. Examination, classification, and treatment of halitosis: clinical perspectives. J Can Dent Assoc. 2000;66:257-61.

14. Suzuki N, Yoneda M, Naito T, Inamitsu T, Yamada K, Okada I, Hatano Y, Iwamoto T, Masuo Y, Fujimoto A, Hirofuji T. Association between oral malodor and psychological characteristics in subjects with neurotic tendencies complaining of halitosis. Int Dent J. 2011;61:57-62.

15. Winkel EG, Van Winkelhoff AJ, Timmerman MF, Van der Velden U, Van der Weijden GA. Amoxicillin plus metronidazole in the treatment of adult periodontitis patients. A double-blind placebo-controlled study. J Clin Periodontol. 2001;28:296-305

16. Araujo CF, Andere NMRB, Dos Santos NCC, Mathias-Santamaria IF, Reis AA, de Oliveira LD, Jardini MAN, Casarin RCV, Santamaria MP. Two different antibiotic protocols as adjuncts to one-stage full-mouth ultrasonic debridement to treat generalized aggressive periodontitis: a pilot randomized controlled clinical trial. J Periodontol. 2019;90:1431-40.

17. Silness J, Löe H. Periodontal disease in pregnancy, II: correlation between oral hygiene and periodontal condition. Acta Odontol Scand. 1964;22:121-35

18. Socransky SS, Haffajee AD. Dental biofilms: difficult therapeutic targets. Periodontol. 2000;2002(28):12-55.

19. Takeshita T, Nakano $Y$, Yamashita Y. Improved accuracy in terminal restriction fragment length polymorphism phylogenetic analysis using a novel internal size standard definition. Oral Microbiol Immunol. 2007;22:419-28.

20. Takeshita T, Kageyama S, Furuta M, Tsuboi H, Takeuchi K, Shibata Y, Shimazaki Y, Akifusa S, Ninomiya T, Kiyohara Y, Yamashita Y. Bacterial diversity in saliva and oral health-related conditions: the Hisayama Study. Sci Rep. 2016;6:22164

21. Asakawa M, Takeshita T, Furuta M, Kageyama S, Takeuchi K, Hata J, Ninomiya T, Yamashita Y. Tongue microbiota and oral health status in community-dwelling elderly adults. mSphere. 2018;3:e00332-18.

22. Edgar RC. UPARSE: highly accurate OTU sequences from microbial amplicon reads. Nat Methods. 2013:10:996-8.

23. Chen T, Yu WH, Izard J, Baranova OV, Lakshmanan A, Dewhirst FE. The Human Oral Microbiome Database: a web accessible resource for investigating oral microbe taxonomic and genomic information. Database (Oxford). 2010;2010:baq013.

24. Lozupone C, Knight R. UniFrac: a new phylogenetic method for comparing microbial communities. Appl Environ Microbiol. 2005;71:8228-35.

25. The R project homepage. https://www.r-project.org.
26. Dou W, Li J, Xu L, Hu K, Sui Z, Wang J, Xu L, Wang S, Yin G. Halitosis and helicobacter pylori infection: a meta-analysis. Medicine (Baltimore). 2016:95:e4233.

27. Serin E, Gumurdulu Y, Kayaselcuk F, Ozer B, Yilmaz U, Boyacioglu S. Halitosis in patients with Helicobacter pylori-positive non-ulcer dyspepsia: an indication for eradication therapy? Eur J Intern Med. 2003;14:45-8.

28. Gasbarrini A, Ojetti V, Pitocco D, Franceschi F, Candelli M, Torre ES, Gabrielli M, Cammarota G, Armuzzi A, Pola R, Pola P, Ghirlanda G, Gasbarrini G. Insulin-dependent diabetes mellitus affects eradication rate of Helicobacter pylori infection. Eur J Gastroenterol Hepatol. 1999;11:713-6.

29. Zaric S, Bojic B, Popovic B, Milasin J. Eradication of gastric Helicobacter pylori ameliorates halitosis and tongue coating. J Contemp Dent Pract. 2015;16:205-9.

30. Hagenfeld D, Koch R, Jünemann S, Prior K, Harks I, Eickholz P, Hoffmann T, Kim TS, Kocher T, Meyle J, Kaner D, Schlagenhauf U, Ehmke B, Harmsen D. Do we treat our patients or rather periodontal microbes with adjunctive antibiotics in periodontal therapy? A 165 rDNA microbial community analysis. PLoS ONE. 2018;13:e0195534.

31. Nakano Y, Yoshimura M, Koga T. Correlation between oral malodor and periodontal bacteria. Microb Infect. 2002;4:679-83.

32. Sakaki-Imamura T, Yano A, Yoshida Y. Production of indole from L-tryptophan and effects of these compounds on biofilm formation by Fusobac terium nucleatum ATCC 25586. Appl Environ Microbiol. 2010;76:4260-8.

33. Lu R, Meng H, Gao X, Xu L, Feng X. Effect of non-surgical periodontal treatment on short chain fatty acid levels in gingival crevicular fluid of patients with generalized aggressive periodontitis. J Periodont Res. 2014;49:574-83.

34. Ishihara K, Miura T, Ebihara Y, Hirayama T, Kamiya S, Okuda K. Shared antigenicity between Helicobacter pylori and periodontopathic Campylobacter rectus strains. FEMS Microbiol Lett. 2001;197:23-7.

35. Tanabe S, Hinode D, Yokoyama M, Fukui M, Nakamura R, Yoshioka M, Grenier D, Mayrand D. Helicobacter pylori and Campylobacter rectus share a common antigen. Oral Microbiol Immunol. 2003;18:79-87.

36. Lee H, Kho HS, Chung JW, Chung SC, Kim YK. Volatile sulfur compounds produced by Helicobacter pylori. J Clin Gastroenterol. 2006;40:421-6.

37. Flores-Treviño CE, Urrutia-Baca VH, Gómez-Flores R, De La Garza-Ramos MA, Sánchez-Chaparro MM, Garza-Elizondo MA. Molecular detection of Helicobacter pylori based on the presence of cagA and vacA virulence genes in dental plaque from patients with periodontitis. J Dent Sci. 2019;14:163-70.

38. Boylan MR, Khalili H, Huang ES, Michaud DS, Izard J, Joshipura KJ, Chan AT. A prospective study of periodontal disease and risk of gastric and duodenal ulcer in male health professionals. Clin Transl Gastroenterol. 2014;5:e49.

\section{Publisher's Note}

Springer Nature remains neutral with regard to jurisdictional claims in published maps and institutional affiliations.

\footnotetext{
Ready to submit your research? Choose BMC and benefit from:

- fast, convenient online submission

- thorough peer review by experienced researchers in your field

- rapid publication on acceptance

- support for research data, including large and complex data types

- gold Open Access which fosters wider collaboration and increased citations

- maximum visibility for your research: over $100 \mathrm{M}$ website views per year
}

At BMC, research is always in progress.

Learn more biomedcentral.com/submissions 